
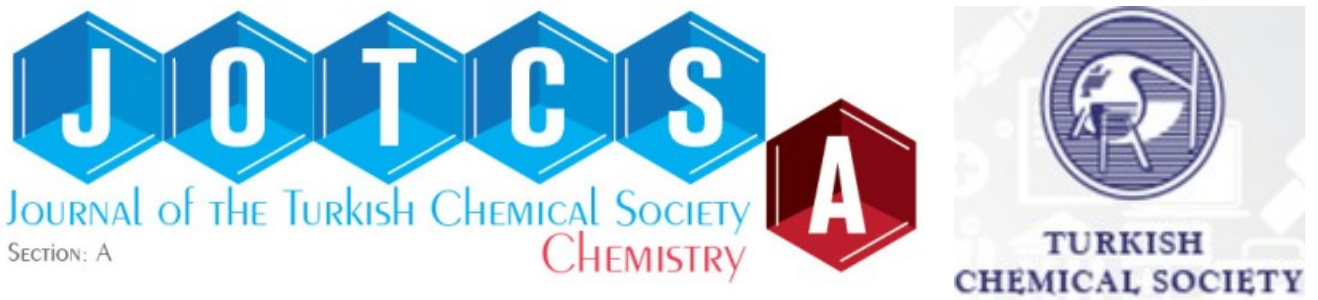

\title{
Simple and sensitive detection of quercetin antioxidant by TEOS coated magnetic $\mathrm{Fe}_{2} \mathrm{O}_{3}$ core-shell
}

\author{
Ahmet ŞENOCAKA* \\ a Department of Chemistry, Gebze Technical University, 41400 Gebze, Kocaeli, Turkey
}

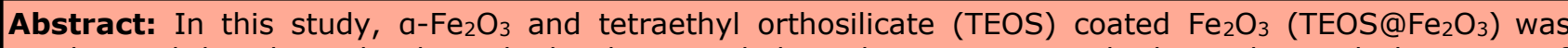
synthesized by the sol-gel method. The morphological properties and electrochemical detection of quercetin antioxidant with $\mathrm{Fe}_{2} \mathrm{O}_{3}$ and TEOS@ $\mathrm{Fe}_{2} \mathrm{O}_{3}$ nanomaterials were evaluated. $\mathrm{TEOS}_{0} @ \mathrm{Fe}_{2} \mathrm{O}_{3} \mathrm{material}$ was modified on a glassy carbon electrode (GCE) for the detection of quercetin with a linear range of 1.0$9.0 \mu \mathrm{M}$ by square wave voltammetry (SWV). TEOS@Fe $\mathrm{O}_{3} / \mathrm{GCE}$ sensor ca 1.6 and 2.5 times more sensitive than $\mathrm{Fe}_{2} \mathrm{O}_{3} / \mathrm{GCE}$ and GCE. The quantification (LOQ) and detection (LOD) limits were found to be 306 and $92 \mathrm{nM}$ for quercetin antioxidant on the TEOS@Fe $\mathrm{O}_{3}$ modified electrode. Quercetin was also determined in an apple tea sample with a standard addition method, and the recovery of quercetin was

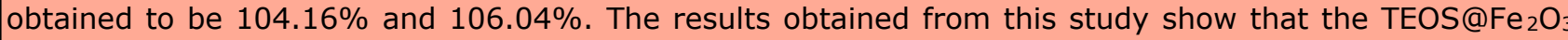
modified electrode examined as a voltammetric sensor was found to be sensitive and straightforward to quercetin.
\end{abstract}

Keywords: Quercetin antioxidant; Magnetic nanoparticle; Electrochemical sensor, TEOS.

Submitted: May 06, 2020. Accepted: May 17, 2020.

Cite this: ŞENOCAK A. Simple and sensitive detection of quercetin antioxidant by TEOS coated magnetic Fe2O3 core-shell. JOTCSA. 2020;7(2):525-34.

DOI: https://doi.org/10.18596/jotcsa.733141.

*Corresponding author. E-mail: asenocak@gtu.edu.tr.

\section{INTRODUCTION}

Magnetite nanoparticles have attracted attention due to potential application in numerous biomedical applications and special physicochemical features, such as contrast agents in magnetic resonance imaging, carriers for targeted drug delivery, the magnetic separation in microbiology, biochemical sensing (1-3). Iron oxides nanoparticles have found extensive interest recently, and these materials often show unique magnetic, physical, catalytic, and optical features (4-6). These non-toxic and cheap nanomaterials are potential applications in high technology and used for enhanced the properties of storage media (7), in drug delivery, biosensors (8), and catalysts (9). The size and magnetic anisotropy of the particles are related to magnetization values of iron oxide nanostructures (10). $\mathrm{Fe}_{2} \mathrm{O}_{3}$ nanoparticles are exceptionally eco-friendly, rich in magnetite nanoparticles, economical, and highly resistant to corrosion, and they were also found to be stable at room temperature (11). Therefore, $\mathrm{Fe}_{2} \mathrm{O}_{3}$ nanoparticles are applied to catalysts and a variety of soft and hard magnetic materials, and they have good biocompatibility $(12,13)$.

Recent studies have been shown that there is increasing interest in preventing diseases such as obesity, cardiovascular, inflammatory processes, cancer, and neurodegenerative disorders (14). These disorders can accelerate as people grow older, and their effects may be decreased by the intake of vegetables and fruits $(15,16)$. A diet containing Vitamin A and polyphenolic compounds, consideration of active nutrients in the prevention of disease because of oxidative stress, may decrease the effect (17). Moreover, the determination of antioxidants has increased to significant importance to protect from these disorders $(18,19)$. Flavonoids are naturally found in fresh vegetables and fruits, and they generally used as a component of health products and food additives (20). They show anti- 
inflammatory and antioxidant properties concerning radical scavenging features of the compounds. Quercetin is a member of the flavonoid family, found in apples, onions, sweet pepper, grapes, celery, and honeysuckle. The antioxidant properties of quercetin have been extensively explored in the past studies $(21,22)$ due to other biological advantages such as anti-tumor, anti-viral, antiallergic activities, reducing blood lipids and blood pressure $(16,23,24)$. For this reason, developing sensitive, fast and straightforward determination methods of quercetin is vitally important.

Quercetin determination was carried out by traditional methods such as ultra-performance liquid chromatography (25), spectrofluorimetry $(26,27)$, and mass spectrometry (28), which are highly selective and sensitive. However, they are timeconsuming, expensive, and complicated sample preparation. Voltammetric techniques are potentially applied for the determination of quercetin because of the electrochemical activity to overcome these difficulties (29). Therefore, $\mathrm{Fe}_{2} \mathrm{O}_{3}$ was coated TEOS to obtain TEOS@ $\mathrm{Fe}_{2} \mathrm{O}_{3}$, which is a spherical material for the determination of quercetin via the electrochemical method for the first time. Due to higher surface area, well-designed material shape, and electroactive metal content, TEOS@ $\mathrm{Fe}_{2} \mathrm{O}_{3}$ was tested in quercetin determination via signal amplification.

Herein, a magnetic nanoparticle of TEOS@ $\mathrm{Fe}_{2} \mathrm{O}_{3}$ has been synthesized and successfully immobilized onto a GCE using an electrochemical sensor. The electrode showed impressive electrocatalytic action for the oxidation of quercetin, which is characterized by the enhancement of the highest current in both cyclic and square wave voltammetry techniques. After optimization, the electrode was used for quantification of quercetin in apple tea sample extracts. Experiments indicated that the TEOS@ $\mathrm{Fe}_{2} \mathrm{O}_{3}$ based sensor was shown excellent electrocatalytic activity to quercetin.

\section{EXPERIMENTAL}

\section{Materials and Characterization Techniques}

$\mathrm{Fe}\left(\mathrm{NO}_{3}\right)_{3} \cdot 9 \mathrm{H}_{2} \mathrm{O}(98 \%)$, citric acid (98\%) and quercetin (99\%) were supplied from Sigma Aldrich, and stock solution of quercetin (concentration of 1 $\mathrm{mM}$ ) was prepared daily. 0.1 M Britton-Robinson (BR) buffer solution, which was used as an electrolyte and prepared by boric, orthophosphoric, and acetic acids in pure water and kept at $4.0^{\circ} \mathrm{C}$. $\mathrm{pH}$ value of buffer solutions was adjusted by $5 \mathrm{M}$ $\mathrm{NaOH}$ with a pH meter (Mettler Toledo, Switzerland). Voltammetric studies were carried by an electrochemical analyzer system of $\mathrm{CH}$ Instruments (CHI440B model, USA) at $25{ }^{\circ} \mathrm{C}$. A three-electrode cell consisting of a counter, reference, and working electrodes are platinum wire, $\mathrm{Ag} / \mathrm{AgCl}$, and TEOS@ $\mathrm{Fe}_{2} \mathrm{O}_{3} / \mathrm{GCE}$, respectively.

Surface morphological properties of $\mathrm{Fe}_{2} \mathrm{O}_{3}$ and TEOS@ $\mathrm{Fe}_{2} \mathrm{O}_{3}$ materials were performed by scanning (SEM) and transmission electron microscopic methods (TEM). The morphology of the synthesized hybrids was studied using an FEI (PHILIPS) XL30 SFEG scanning electron microscope. TEM images were obtained using an FEI TALOS F200S TEM instrument (accelerating voltage of $200 \mathrm{kV}$ ).

\section{Preparation of $\mathrm{Fe}_{2} \mathrm{O}_{3}$ and TEOS@ $\mathrm{Fe}_{2} \mathrm{O}_{3}$}

Hematite $\left(\mathrm{a}-\mathrm{Fe}_{2} \mathrm{O}_{3}\right)$ nanoparticles were prepared according to a simple method given in the literature with a slight modification $(30,31)$. Briefly, $10 \mathrm{mmol}$ $\mathrm{Fe}\left(\mathrm{NO}_{3}\right)_{3} .9 \mathrm{H}_{2} \mathrm{O}$ and $12.5 \mathrm{mmol}$ citric acid was dissolved in $60 \mathrm{~mL}$ of pure water and mixed ultrasonically for about 20 minutes. Then, $10 \mathrm{~mL}$ of ethanol was added, and the $\mathrm{pH}$ was adjusted to 5 with ammonia. The solution was taken into a beaker and boiled until obtaining a gel. It was transferred into an oven at $95{ }^{\circ} \mathrm{C}$ for drying. The dried gel was purged with pure $\mathrm{N}_{2}$ gas for 30 minutes and placed to a tube furnace annealed to $400{ }^{\circ} \mathrm{C}$ for 3 hours. The final product was $1.5 \mathrm{~g}$ of $\mathrm{a}-\mathrm{Fe}_{2} \mathrm{O}_{3}$. The prepared $\mathrm{a}-\mathrm{Fe}_{2} \mathrm{O}_{3}$ particles were coated with silica using a sol-gel method (32). In a typical procedure, $100 \mathrm{mg}$ of $\mathrm{Fe}_{2} \mathrm{O}_{3}$ was dispersed in absolute ethanol solution by ultrasonic bath, and $750 \mu \mathrm{L}$ of $\mathrm{NH}_{4} \mathrm{OH}$ and $400 \mu \mathrm{L}$ of TEOS have added the suspension (Scheme 1, inset). The morphological analysis of samples was characterized by SEM and TEM. 


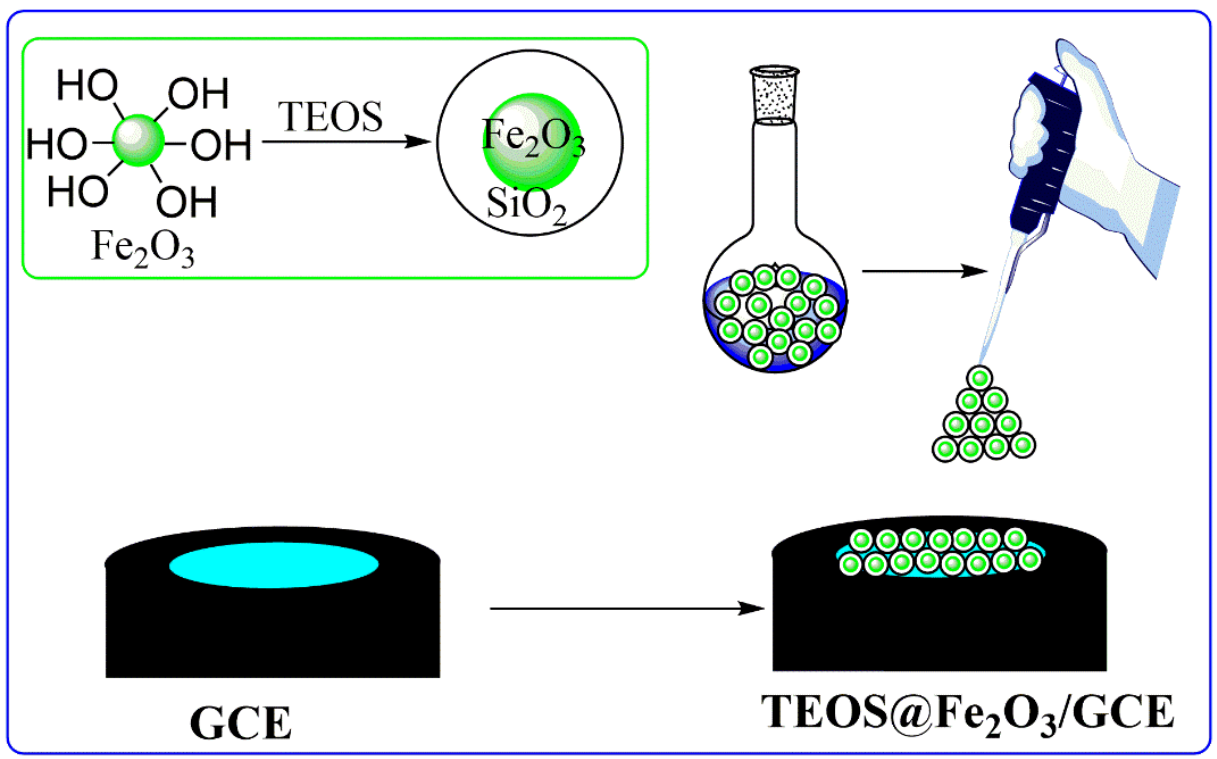

Scheme 1. Schematic representation of the synthesis of TEOS@ $\mathrm{Fe}_{2} \mathrm{O}_{3}$ material and fabrication of the sensor.

\section{Preparation of the TEOS@ $\mathrm{Fe}_{2} \mathrm{O}_{3}$ modified GCE}

Scheme 1 depicts the fabrication procedure of the sensor based on the investigated TEOS@Fe $\mathrm{O}_{3}$. The mirror-like clean surface of GCE was obtained with different size alumina powders ranging between 1.0 to $0.05 \mu \mathrm{m}$. Then GCE was cleaned after each polishing with ultra-pure water and ultrasonicated in acetone, $\mathrm{HNO}_{3}$ solution $(1: 1, \mathrm{v} / \mathrm{v})$, and doubledistilled water, respectively. The cleaned GCE was then dried at room temperature until use. The TEOS@ $\mathrm{Fe}_{2} \mathrm{O}_{3}$ modified GCE was obtained by dropcasting method. $2 \mathrm{mg}$ of TEOS@ $\mathrm{Fe}_{2} \mathrm{O}_{3}$ was placed into $1.0 \mathrm{~mL}$ ultra-pure water and stirred in an ultrasonic bath for 15 min to obtain well-dispersed 2 $\mathrm{mg} / \mathrm{mL}$ suspension. An amount of $10 \mu \mathrm{L}$ brownishred suspension was transferred onto the cleaned surface of the electrode and dried at $40{ }^{\circ} \mathrm{C}$. The obtained sensor electrode was taken as TEOS@ $\mathrm{Fe}_{2} \mathrm{O}_{3} / \mathrm{GCE}$.

\section{Real samples assay procedure}

Apple tea sample was purchased from a local market and weighed as $0.5 \mathrm{~g}$ and dissolved in ethanol $(10.0 \mathrm{~mL})$. The sample solution was well dispersed by an ultrasonic bath for $20 \mathrm{~min}$. The supernatant of the dispersion was separated by centrifugation for $4 \mathrm{~min}$ at $3000 \mathrm{rpm}$. The sample solution was used to determination of quercetin without any further treatment. Electrochemical determination of quercetin was performed in the solution by the SWV technique from 0.0 to $1.0 \mathrm{~V}$. All real sample detection measurements were applied three times at room temperature, and average values were taken to calculate the amount of quercetin antioxidants.

\section{RESULTS AND DISCUSSION}

\section{Morphological Characterization of $\mathrm{Fe}_{2} \mathrm{O}_{3}$ and} TEOS@Fe $\mathrm{O}_{3}$

Morphological characterization of $\mathrm{Fe}_{2} \mathrm{O}_{3}$ and TEOS@ $\mathrm{Fe}_{2} \mathrm{O}_{3}$ were investigated by scanning SEM TEM (Figure 2). Figure 2a demonstrates a typical SEM image of the a- $\mathrm{Fe}_{2} \mathrm{O}_{3}$ samples. As seen in this figure, pores structure can be monitored with an average size of 50-60 nm. SEM images also clearly showed the nanostructural homogeneities and remarkably unique neck-structured morphology, which could be the advantage of the penetration of antioxidant molecules. Figure $1 \mathrm{~b}$ depicts the SEM image of TEOS@ $\mathrm{Fe}_{2} \mathrm{O}_{3}$ particles. A large number of iron particles are monitored on the Si substrate with diameters in the range of $250-400 \mathrm{~nm}$. Figure 2c and $2 \mathrm{~d}$ show TEM images of the $\mathrm{a}-\mathrm{Fe}_{2} \mathrm{O}_{3}$ and TEOS@ $\mathrm{Fe}_{2} \mathrm{O}_{3}$ particles. Although $\mathrm{Fe}_{2} \mathrm{O}_{3}$ nanoparticles can be obtained as the shaping of many rough surfaces and different sizes, TEOS@ $\mathrm{Fe}_{2} \mathrm{O}_{3}$ particles have almost uniform shapes. The spherical TEOS@ $\mathrm{Fe}_{2} \mathrm{O}_{3}$ particle sizes were also confirmed by TEM. Besides, elemental analysis of the spherical structures, EDX analysis (installed in SEM) was carried out. The EDX analysis of the $a-\mathrm{Fe}_{2} \mathrm{O}_{3}$ particles represents the atomic percentage (\%) of the $\mathrm{O}, \mathrm{Fe}$ is $2: 1$, and the percentage of $\mathrm{Fe}, \mathrm{O}$, and $\mathrm{Si}$ in TEOS@ $\mathrm{Fe}_{2} \mathrm{O}_{3}$ are 2:5:3.

\section{Electrochemical Sensor Examination Tests of TEOS@ $\mathrm{Fe}_{2} \mathrm{O}_{3}$ Material to Quercetin}

The cleaned GCE was coated by $10 \mu \mathrm{L}$ drop of the TEOS@ $\mathrm{Fe}_{2} \mathrm{O}_{3}$ suspension ( $2 \mathrm{mg} / \mathrm{mL}$ ) in ultra-pure water to provide the TEOS@ $\mathrm{Fe}_{2} \mathrm{O}_{3} / \mathrm{GCE}$ sensor. The electrochemical sensor properties of TEOS@ $\mathrm{Fe}_{2} \mathrm{O}_{3} / \mathrm{GCE}$ towards $6 \mu \mathrm{M}$ quercetin were investigated by SWV methods with bare $\mathrm{GCE}, \mathrm{Fe}_{2} \mathrm{O}_{3} /$ GCE in a BR buffer solution ( $\mathrm{pH}=2$ ) comparatively. 
sensitive than pristine GCE and $\mathrm{Fe}_{2} \mathrm{O}_{3} / \mathrm{GCE}$, respectively (Figures $1 \mathrm{a}$ and $1 \mathrm{~b}$ ).
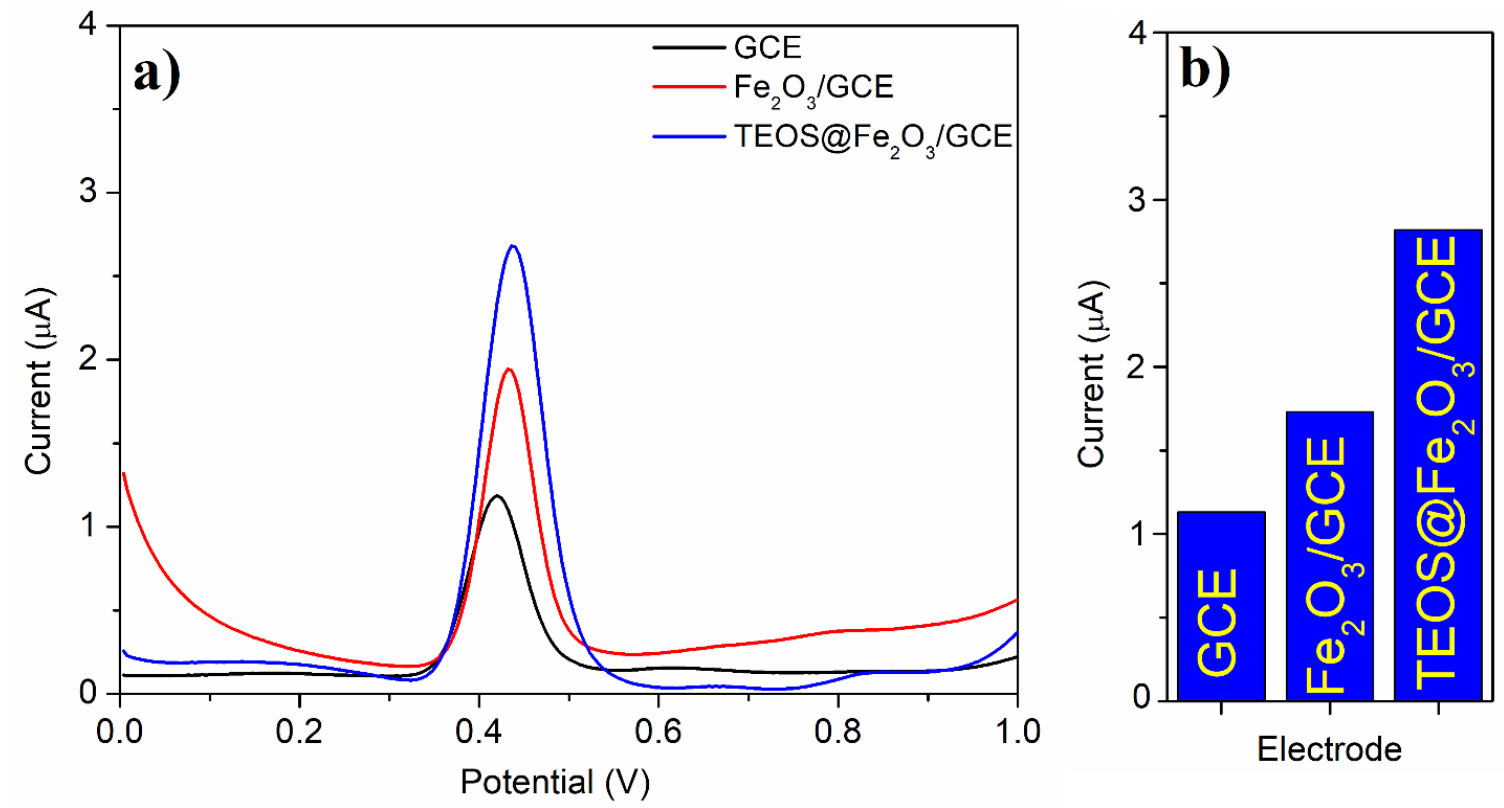

Figure 1. a) SWV response to $6 \mu \mathrm{M}$ quercetin ( $\mathrm{pH}=2$ ) TEOS@ $\mathrm{Fe}_{2} \mathrm{O}_{3} / \mathrm{GCE}$ in comparison with bare GCE and $\mathrm{Fe}_{2} \mathrm{O}_{3} / \mathrm{GCE}$, b) their column graph.
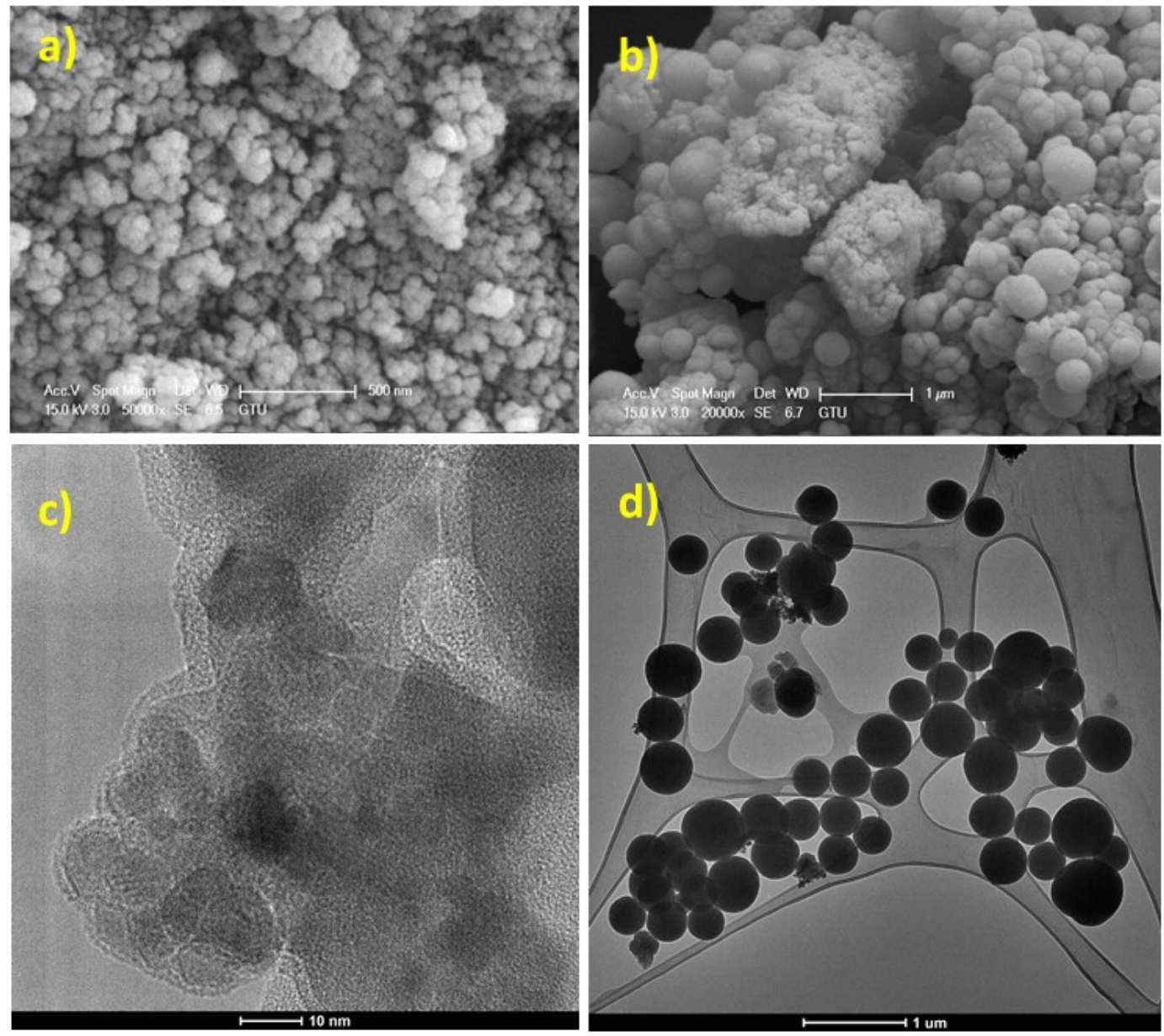

Figure 2. a) and b) SEM images, c) and d) TEM of images of $\mathrm{Fe}_{2} \mathrm{O}_{3}$ and TEOS@ $\mathrm{Fe}_{2} \mathrm{O}_{3}$ 
The investigation of $\mathrm{pH}$ impact on voltammetric sensor features was also evaluated in BR buffer solution, and adjustments of $\mathrm{pH}$ were performed by $\mathrm{NaOH}$ solution $(5.0 \mathrm{M})$. Figure $3 a$ depicts the SWV responses of quercetin in the $\mathrm{BR}$ solutions with different $\mathrm{pH}$ values (2-7). The optimal $\mathrm{pH}$ value is found to be 2 because of better and higher peak current. When the acidic $\mathrm{pH}$ value comes out, the interaction between -OH functional groups in quercetin and electron-deficient boron atoms of in the BR are increased (33). Thus, it can be said that the reaction between the quercetin and the TEOS@ $\mathrm{Fe}_{2} \mathrm{O}_{3}$ is a $\mathrm{pH}$-dependent reaction.

Moreover, higher hydrophobic interaction and hydrogen bond formation occurs between spherical TEOS@ $\mathrm{Fe}_{2} \mathrm{O}_{3}$ nanomaterial. Also, mass transfer of quercetin via diffusion happened very hard because the at basic and neutral $\mathrm{pH}$ can limit the surface of the electrode and causes a decrease of the peak current. Due to the inhibition of quercetin antioxidant transfer by the absorption with $\mathrm{OH}$ functional groups, peak current values decreased suddenly. Quercetin's oxidation peak currents are almost invisible at high $\mathrm{pH}$, along with a decrease of interaction between the buffer solution and $\mathrm{OH}$ of the quercetin (34). Therefore, the relationship between peak current and $\mathrm{pH}$ values (range of 2 to 7) was shown in Figure $\mathbf{3 b}$, which demonstrates a linear decrease with a slope of $60.80 \mathrm{mV} / \mathrm{pH}$. This value is very close to $59 \mathrm{mV} / \mathrm{pH}$ (Nernstian behavior) $(29,35)$. This voltammetric response has the same numbers of proton and electron ( $y=-$ $0.0608 x+0.5896, R^{2}=0.9961$ ) and in harmony with the electro-oxidation mechanism of quercetin (29).
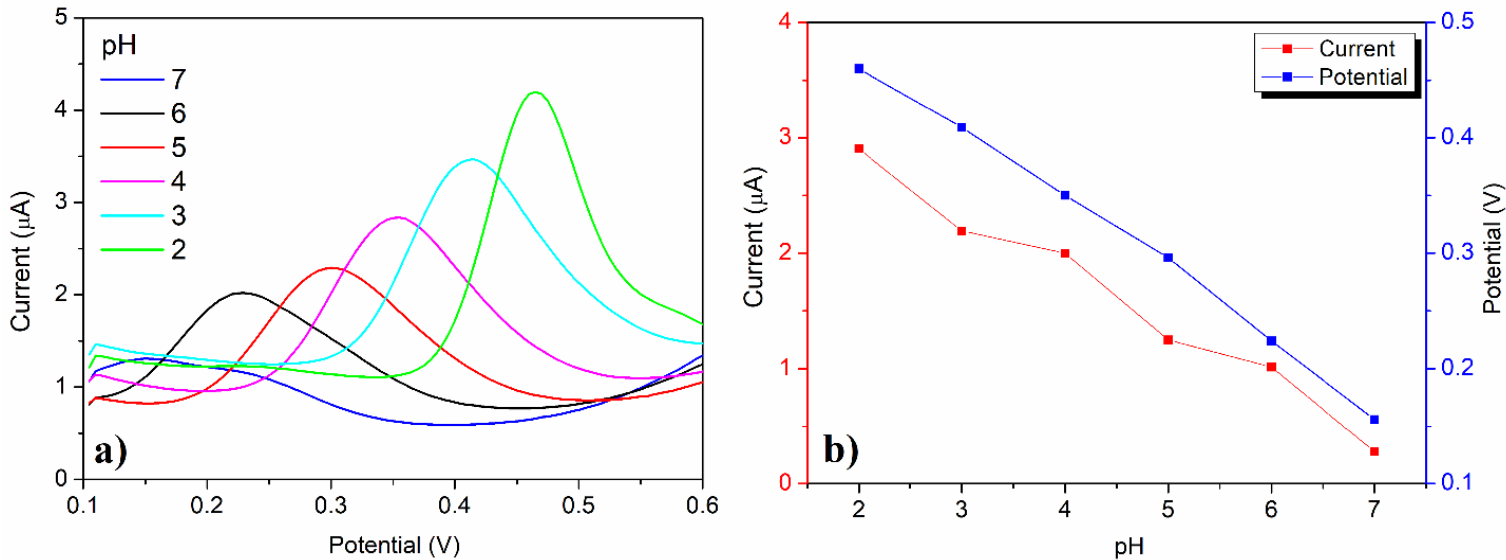

Figure 3. a) SWV responses at different $\mathrm{pH}$ values in the range of 2-7 and b) changes in $\mathrm{pH}$ with peak currents and peak potentials.

Not only electrokinetic behavior, both also analytical features performed by SWV and CV techniques. Figure $4 a$ demonstrates the SWV responses obtaining by different concentrations of quercetin on the TEOS@ $\mathrm{Fe}_{2} \mathrm{O}_{3} / \mathrm{GCE}$ at the supporting electrolyte as a $\mathrm{pH} 2.0 \mathrm{BR}$ buffer solution. As seen, this figure with a concentration of quercetin ranging from 1.0 to $9.0 \mu \mathrm{M}$ was linearly increasing of peak current (Figure 4b). The LOQ and LOD of quercetin antioxidant were calculated as 306 and $92 \mathrm{nM}$ (y $=0.4632 x-0.0391, R^{2}=0.9956$ ) respectively.
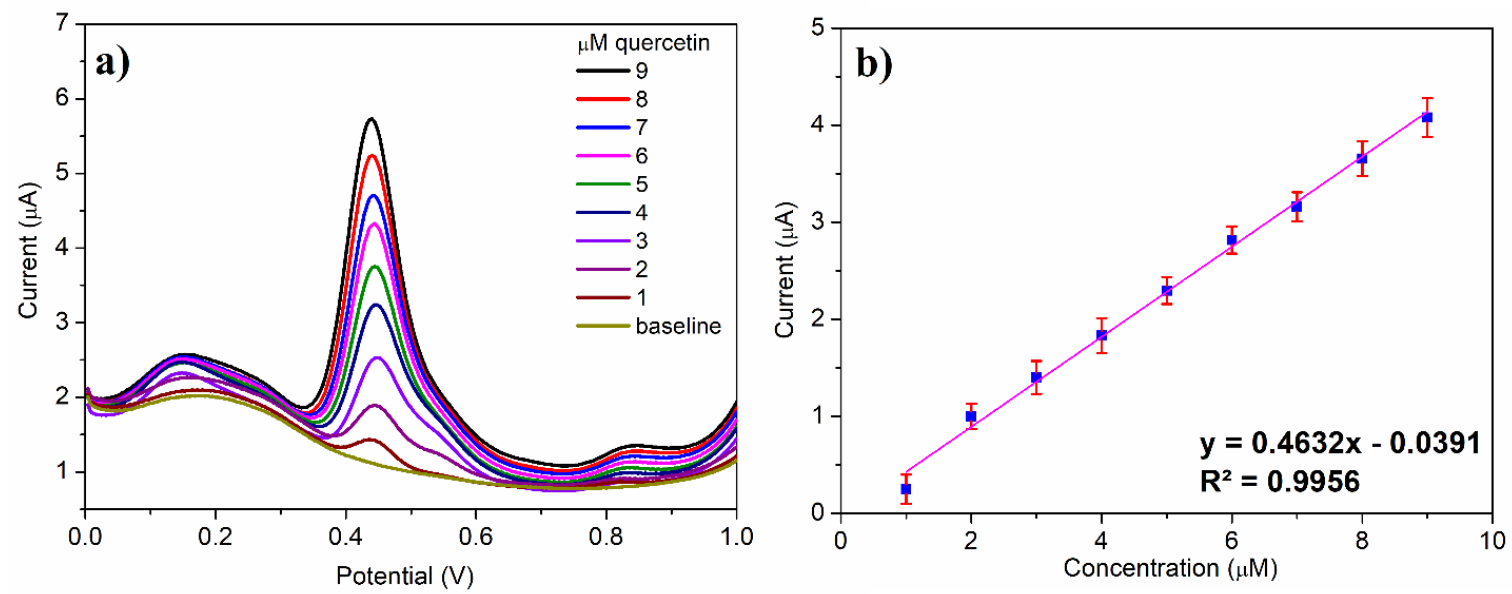

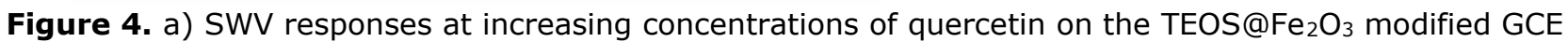
and b) calibration graphs corresponding to (a). 
CV measurements were carried out to determine the impact on the redox reaction mechanism of quercetin by the scan for gaining further information about the relationship between the scan rate and peak current. Figure $5 \mathrm{a}$ demonstrates the electrochemical measurements containing $6 \mu \mathrm{M}$ quercetin, which was performed at the several scan rates (in the ranging from 25 to $500 \mathrm{mV} / \mathrm{s}$ ) in the buffer $(\mathrm{pH}=2.0)$. As seen in Figure $5 \mathrm{~b}$, the peak current was increased linearly with an increase of the scan rate ( $R^{2}$ values were found to be 0.9979 and 0.9989 for oxidation and reduction). This linear correlation was pointed out that the electrooxidation process of quercetin is controlled by adsorption in agreement with the previous works (36). Also, the quercetin has reversible electrode processes because it exhibited two peaks, which are an anodic peak at $490 \mathrm{mV}$ and a cathodic peak at $430 \mathrm{mV}$
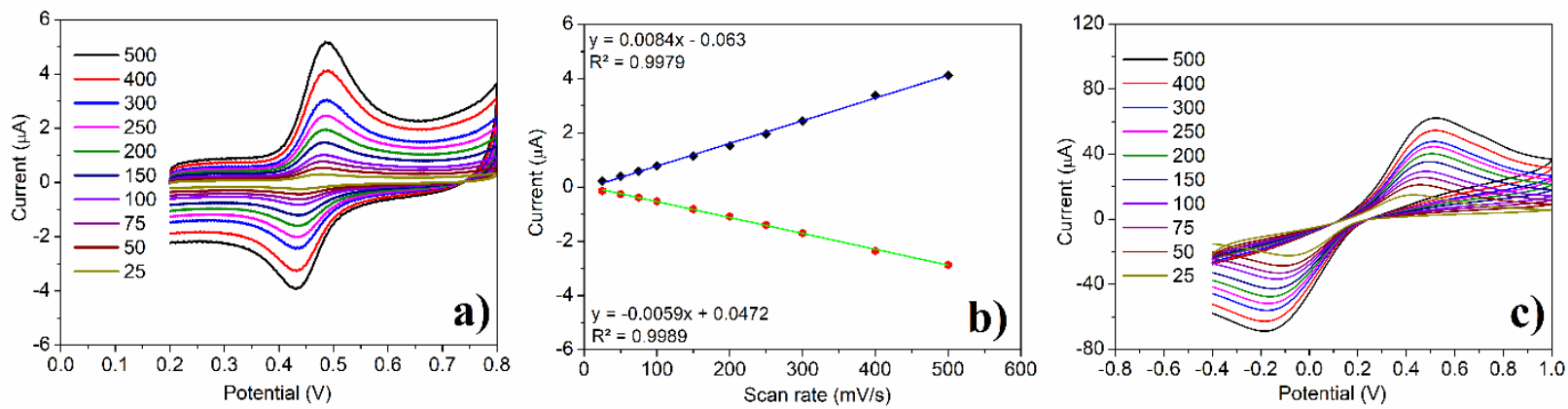

Figure 5. a) CV responses of $6 \mu \mathrm{M}$ quercetin at various scan rates, b) Plot of Ipa and Ipc and c) CV of TEOS@ $\mathrm{Fe}_{2} \mathrm{O}_{3} / \mathrm{GCE}$ in a solution containing $\mathrm{K}_{3}\left[\mathrm{Fe}(\mathrm{CN})_{6}\right]$ and $\mathrm{KCl}$ at different scan rates in the ranging from 25 to $500 \mathrm{mV} / \mathrm{s}$.

$\mathrm{CV}$ at different scan rates was performed to estimate the specific surface area of TEOS@ $\mathrm{Fe}_{2} \mathrm{O}_{3}$ modified GCE in a solution containing $\mathrm{K}_{3}\left[\mathrm{Fe}(\mathrm{CN})_{6}\right]$ and $\mathrm{KCl}$ by Randles-Sevcik equation (Figure $5 \mathrm{c}$ ). The concentrations of $\mathrm{KCl}$ and $\mathrm{K}_{3}\left[\mathrm{Fe}(\mathrm{CN})_{6}\right]$ were $0.1 \mathrm{M}$ and $5.0 \mathrm{mM}$. where $A, D_{0}$, and $C_{0}$ are the specific surface area $\left(\mathrm{cm}^{2}\right)$ of the TEOS@ $\mathrm{Fe}_{2} \mathrm{O}_{3}$ modified $\mathrm{GCE}$, the concentration of $\mathrm{K}_{3}\left[\mathrm{Fe}(\mathrm{CN})_{6}\right](5.0 \mathrm{mM})$ and diffusion coefficient $\left(7.6 \times 10^{-6} \mathrm{~cm}^{2} / \mathrm{s}\right)$. The activated surface area of TEOS@ $\mathrm{Fe}_{2} \mathrm{O}_{3}-\mathrm{GCE}$ was estimated as $0.103 \mathrm{~cm}^{2}$ from the Randles-Sevcik equation by calculating the slope of Ip vs $U^{1 / 2}$ plot. This surface area was more remarkable than the unmodified GCE $\left(0.071 \mathrm{~cm}^{2}\right)$.

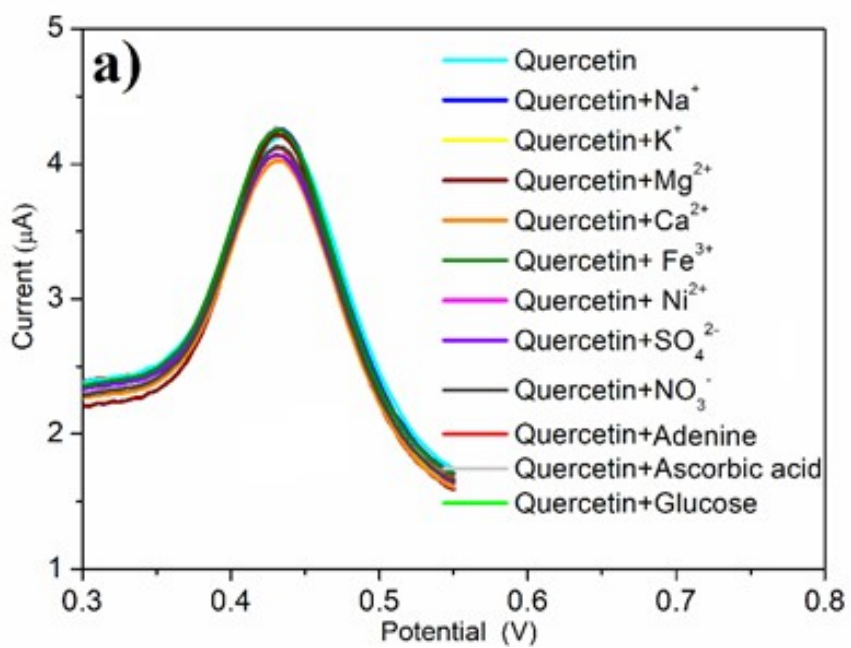

Figure 6. a) DPV curves in the presence of anions, cations, and bioanalytes and b) their column graph.
Repeatability, Stability, Selectivity, and Comparison Of TEOS@ $\mathrm{Fe}_{2} \mathrm{O}_{3} / \mathrm{GCE}$ Sensor

Anions and cations such as $\mathrm{SO}_{4}{ }^{2-}, \mathrm{NO}_{3}{ }^{-}, \mathrm{K}^{+}, \mathrm{Na}^{+}$, $\mathrm{Mg}^{2+}, \mathrm{Ca}^{2+}, \mathrm{Fe}^{3+}, \mathrm{Ni}^{2+}$ were examined to show the selectivity of the TEOS@ $\mathrm{Fe}_{2} \mathrm{O}_{3}$ modified GCE sensor at $25{ }^{\circ} \mathrm{C}$. Selectivity experiments were carried out by SWV method using $10 \mathrm{mM}$ of anions and metal ions stock solutions in ultra-pure water. Besides, another interfering study was done in the presence of adenine purine base and ascorbic acid, and glucose solutions at concentration of $1 \mathrm{mM}$ in water. Anions, metal ions and other interfering molecules had no significant effect $(<4 \%)$ on the electrochemical response on $6 \mu \mathrm{M}$ quercetin (Figure $6 \mathrm{a}$ and $\mathrm{b}$ ).

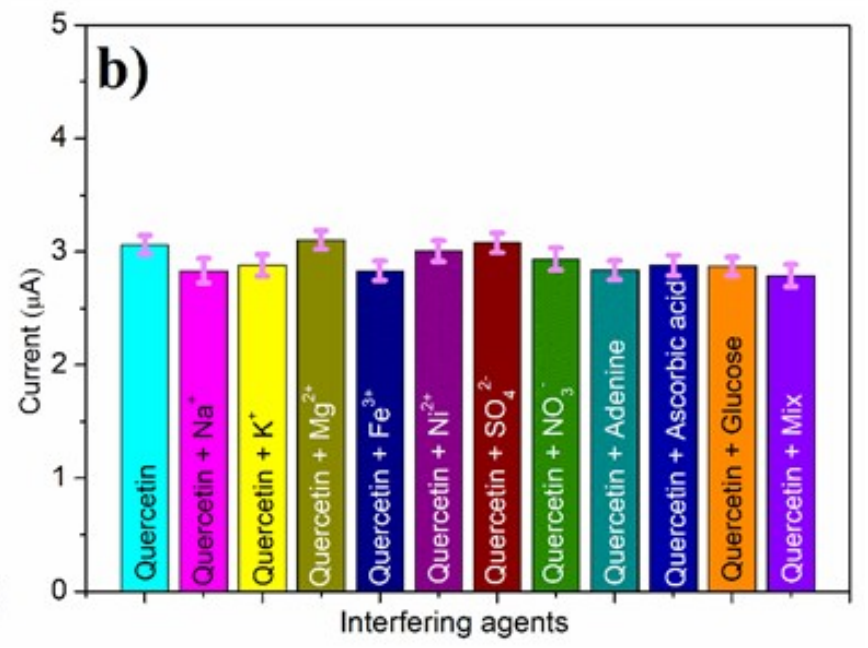


SWV technique was performed in the stability experiment of the sensor every weekday for the determination of quercetin. The electrochemical responses measured in a pH of 2 on TEOS@ $\mathrm{Fe}_{2} \mathrm{O}_{3}$ modified GCE at $25^{\circ} \mathrm{C}$, which did not demonstrate any significant changes in comparison with the beginning response. RSD (Relative Standard Deviation) of the peak current values was found to be $4.1 \%$. Moreover, the repeatability test was done by 7 successive SWV of $6.0 \mu M$ quercetin on TEOS@ $\mathrm{Fe}_{2} \mathrm{O}_{3} / \mathrm{GCE}$, and the RSD was calculated to be $3.5 \%$. It can be concluded that the results from these measurements TEOS@ $\mathrm{Fe}_{2} \mathrm{O}_{3} / \mathrm{GCE}$ sensor showed high repeatability and stability for the determination of quercetin.

Table 1. Comparison of present electrochemical sensors with other reported methods for the determination of quercetin in various samples.

$\begin{array}{ccccc}\text { Methods } & \text { Working Electrode } & \text { LOD (nM) } & \text { Sample } & \text { References } \\ \text { SWV } & \text { TEOS@Fe } \mathrm{O}_{3} / \mathrm{GCE} & 92 & \text { Apple Tea } & \text { This work } \\ \text { SWV } & \text { Co nanoparticle/GCE } & 100 & \text { Tablet and urine } & (37) \\ \text { SWV } & \text { NiO-CNT/CPE } & 30 & \begin{array}{c}\text { Onion, apple and } \\ \text { capsule }\end{array} & (38) \\ \text { DPV } & \text { MIP-GO/GCE } & 48 & \text { Apple juice } & (39) \\ \text { DPV } & \begin{array}{c}\text { Carbon@Fe } \\ \text { nanoparticle/GCE. }\end{array} & 150 & \text { Human urine } & (40)\end{array}$

MIP-GO: Molecularly imprinted polymer incorporated graphene oxide, CNT: Carbon nanotube, CPE: Carbon paste electrode.

TEOS@ $\mathrm{Fe}_{2} \mathrm{O}_{3} / \mathrm{GCE}$ sensor system was compared with the other techniques data on the determination of quercetin given in Table 1 . The obtained outcomes in this study demonstrated that TEOS coated $\mathrm{Fe}_{2} \mathrm{O}_{3}$ sensor system had excellent properties for the selective and sensitive determination of quercetin. The suggested TEOS@ $\mathrm{Fe}_{2} \mathrm{O}_{3} / \mathrm{GCE}$ had some benefits in terms of LOD and linear range. In most quercetin determination studies, electrode modifications were done by carbon nanotube, graphene oxide, and metal nanoparticles. As known, carbon nanotubes have high toxicity, and graphene is expensive and challenging to synthesize. This sensor system has more sensitivity with a high surface area, but their stabilities are very low.

Moreover, some other metal nanoparticles containing studies were available in the literature among them. The TEOS@ $\mathrm{Fe}_{2} \mathrm{O}_{3} / \mathrm{GCE}$ was suggested in this study. TEOS@ $\mathrm{Fe}_{2} \mathrm{O}_{3}$ modified GCE demonstrated very high stability to evaluate quercetin in the apple tea sample. Moreover, the TEOS@ $\mathrm{Fe}_{2} \mathrm{O}_{3}$ modified GCE was easy to prepare, cheaper, and fast electron transfer between quercetin and its surface compared to the electrodes.

\section{Sample Analysis}

The applicability of the TEOS@ $\mathrm{Fe}_{2} \mathrm{O}_{3}$ modified GCE sensor in a commercially available apple tea sample was performed via standard addition method, as reported in (41). Tea sample was weighted as $0.5 \mathrm{~g}$ and thrown in a $10 \mathrm{~mL}$ ethanol. For better dissolution, the suspension was kept in an ultrasonic bath for an hour and centrifuged with $3000 \mathrm{rpm}$ speed. Then the supernatant of the sample suspension was separated from the suspension, and the solution was used to determine quercetin without any treatment by SWV technique from 0.0 to $1.0 \mathrm{~V}$. $100 \mu \mathrm{L}$ of the apple tea sample solution was added in a voltammetric cell to determine the amount of quercetin, and $1.0 \mu \mathrm{M}$ of quercetin was added to the cell. The addition process of quercetin was repeated two times to $100 \mu \mathrm{L}$ sample containing BR buffer solution. Average data and RSD $(<5 \%)$ were estimated through successive measurements (Table $\mathbf{2}$ ). Moreover, the recovery of the measurements on the detection of quercetin was calculated as $104.16 \%$ and $106.04 \%$. According to the real sample measurements, the suggested the TEOS@ $\mathrm{Fe}_{2} \mathrm{O}_{3}$ modified GCE is fast, accurate, and efficient for the determination of quercetin.

\section{CONCLUSION}

In this study, TEOS-coated $\mathrm{Fe} 2 \mathrm{O} 3$ to obtain spherical nanomaterials. A voltammetric determination of low concentrations of quercetin was performed using TEOS@Fe2O3 material modified GCE. The selectivity of TEOS@Fe2O3 modified GCE sensor to quercetin was examined in the presence of different anions, cations, and bioanalytes at the optimum operating conditions. The suggested protocol shows the successful application of TEOS@Fe2O3 modified GCE for the determination of quercetin in real samples with excellent selectivity and sensitivity due to its high synergistic effect of metal nanoparticles and TEOS. Also, reproducibility and stability of the sensor are excellent. 
Table 2. Examples of quercetin detection by SWV on TEOS@ $\mathrm{Fe}_{2} \mathrm{O}_{3}$ modified GCE in apple tea sample.

\begin{tabular}{cccc} 
Addition $(\boldsymbol{\mu M})$ & Measured $(\boldsymbol{\mu M})$ & Recovery (\%) & RSD (\%, $\mathbf{n = 3})$ \\
\hline 0.00 & $1.18 \pm 0.04$ & - & - \\
1.00 & $2.22 \pm 0.04$ & 104.16 & 4.19 \\
2.00 & $3.30 \pm 0.05$ & 106.04 & 4.07 \\
\hline
\end{tabular}

\section{REFERENCES}

1. Gao M, Li W, Dong J, Zhang Z, Yang B. Synthesis and characterization of superparamagnetic Fe304@ SiO2 core-shell composite nanoparticles. World Journal of Condensed Matter Physics. 2011;1(2):49-54.

2. Gupta AK, Gupta M. Synthesis and surface engineering of iron oxide nanoparticles for biomedical applications. Biomaterials. 2005;26(18):3995-4021.

3. Sajjadi S, Khataee A, Bagheri N, Kobya M, Şenocak A, Demirbas $E$, et al. Degradation of diazinon pesticide using catalyzed persulfate with Fe304@MOF-2 nanocomposite under ultrasound irradiation. Journal of Industrial and Engineering Chemistry. 2019;77:280-90.

4. Carraro G, Barreca D, Comini E, Gasparotto A, Maccato C, Sada C, et al. Controlled synthesis and properties of $\beta-\mathrm{Fe} 2 \mathrm{O} 3$ nanosystems functionalized with $\mathrm{Ag}$ or Pt nanoparticles. CrystEngComm. 2012;14(20):6469-76.

5. Kemer B, Demir E. A novel potentiometric $\mathrm{pH}$ electrode based on sulfated natural Fe304 and analytical application in food samples. Journal of Food Measurement and Characterization. 2018; 12(4):2256-62.

6. Surowiec Z, Gac W, Wiertel M. The synthesis and properties of high surface area Fe2O3

materials. Acta Physica Polonica A. 2011;119(1):1820.

7. Ziolo RF, Giannelis EP, Weinstein BA, O'Horo MP, Ganguly BN, Mehrotra V, et al. Matrix-Mediated Synthesis of Nanocrystalline

$\mathrm{y}-\mathrm{Fe}<\mathrm{sub}>2</$ sub $>0<$ sub $>3</$ sub $>$ : A New Optically Transparent Magnetic Material. Science. 1992;257(5067):219-23.

8. McBain SC, Yiu HH, Dobson J. Magnetic nanoparticles for gene and drug delivery. International journal of nanomedicine. $2008 ; 3(2): 169$.

9. Lu Y, Yin Y, Mayers BT, Xia Y. Modifying the Surface Properties of Superparamagnetic Iron Oxide
Nanoparticles through A Sol-Gel Approach. Nano Letters. 2002;2(3):183-6.

10. Cornejo D, Padrón-Hernández E. Study of magnetization process in ordered Fe nanowire arrays. Journal of Magnetism and Magnetic Materials. 2007;316(2):e48-e51.

11. Demir E. A Simple and Sensitive Square Wave Stripping Pathway for the Analysis of Desmedipham Herbicide by Modified Carbon Paste Electrode Based on Hematite (a-Fe2O3

Nanoparticles). Electroanalysis. 2019;31(8):154553.

12. Liao X, Luo J, Wu J, Fan T, Yao Y, Gao F, et al. A sensitive DNAzyme-based electrochemical sensor for $\mathrm{Pb} 2+$ detection with platinum nanoparticles decorated $\mathrm{TiO} 2 / \mathrm{a}-\mathrm{Fe} 2 \mathrm{O} 3$ nanocomposite as signal labels. Journal of Electroanalytical Chemistry. 2018;829:129-37.

13. Nomnotho J, Sabela $M$, Kanchi S, Mdluli $P$, Xhakaza M, Arodola O, et al. MWCNTs- Fe2O3 nanoparticles nanohybrids based highly sensitive electrochemical sensor for the detection of kaempferol in broccoli samples. Turkish Journal of Chemistry. 2019;43:1229-43.

14. DEMIR E. Sensitive and Selective Pathway of Total Antioxidant Capacity in Commercially Lemon, Watermelon and Mango-pineapple Cold Teas by Square Wave Adsorptive Stripping Voltammetry. Gazi University Journal of Science.

2019;32(4):1123-36.

15. Lino FMA, de Sá LZ, Torres IMS, Rocha ML, Dinis TCP, Ghedini PC, et al. Voltammetric and spectrometric determination of antioxidant capacity of selected wines. Electrochimica Acta. $2014 ; 128: 25-31$.

16. Mosleh M, Ghoreishi SM, Masoum S, Khoobi A. Determination of quercetin in the presence of tannic acid in soft drinks based on carbon nanotubes modified electrode using chemometric approaches. Sensors and Actuators B: Chemical. 2018;272:60511.

17. Kuyumcu Savan E. Square Wave

Voltammetric (SWV) Determination of Quercetin in Tea Samples at a Single-Walled Carbon Nanotube 
(SWCNT) Modified Glassy Carbon Electrode (GCE). Analytical Letters. 2020;53(6):858-72.

18. Morosanu AC, Benchea AC, Babusca D, Dimitriu DG, Dorohoi DO. Quantum-Mechanical and Solvatochromic Characterization of Quercetin. Analytical Letters. 2017;50(17):2725-39.

19. Şenocak A, Basova T, Demirbas E, Durmuş $M$. Direct and Fast Electrochemical Determination of Catechin in Tea Extracts using SWCNT-

Subphthalocyanine Hybrid Material. Electroanalysis. 2019;31(9):1697-707.

20. Liu C, Zhang Y, Zhang P, Wang Y. Evaluating Modeling Units and Sub-word Features in Language Models for Turkish ASR2018. 414-8 p.

21. Manokaran J, Muruganantham R, Muthukrishnaraj A, Balasubramanian N. Platinumpolydopamine @SiO2 nanocomposite modified electrode for the electrochemical determination of quercetin. Electrochimica Acta. 2015;168:16-24

22. Ponnaiah SK, Periakaruppan P. A glassy carbon electrode modified with a copper tungstate and polyaniline nanocomposite for voltammetric determination of quercetin. Microchimica Acta. 2018;185(11):524.

23. Ji Y, Li Y, Ren B, Liu X, Li Y, Soar J. Nitrogen-doped graphene-ionic liquid-glassy carbon microsphere paste electrode for ultra-sensitive determination of quercetin. Microchemical Journal. 2020;155:104689.

24. Yao $Z$, Yang $X$, Liu $X$, Yang $Y$, Hu $Y$, Zhao $Z$. Electrochemical quercetin sensor based on a nanocomposite consisting of magnetized reduced graphene oxide, silver nanoparticles and a molecularly imprinted polymer on a screen-printed electrode. Mikrochim Acta [Internet]. 2017 2017/12//; 185(1):[70 p.]. Available from: http://europepmc.org/abstract/MED/29594565, https://doi.org/10.1007/s00604-017-2613-5.

25. Jing J, Shi Y, Zhang Q, Wang J, Ruan J. Prediction of Chinese green tea ranking by metabolite profiling using ultra-performance liquid chromatography-quadrupole time-of-flight mass spectrometry (UPLC-Q-TOF/MS). Food Chemistry. 2017;221:311-6.

26. Abdullah AA, Yardım Y, Şentürk Z. The performance of cathodically pretreated boron-doped diamond electrode in cationic surfactant media for enhancing the adsorptive stripping voltammetric determination of catechol-containing flavonoid quercetin in apple juice. Talanta. 2018;187:156-64.

27. Ravichandran $R$, Rajendran $M$, Devapiriam D. Antioxidant study of quercetin and their metal complex and determination of stability constant by spectrophotometry method. Food Chemistry. 2014;146:472-8

28. Pilařová $\mathrm{V}$, Plachká $\mathrm{K}$, Chrenková $\mathrm{L}$, Najmanová I, Mladěnka $P$, Švec $F$, et al.

Simultaneous determination of quercetin and its metabolites in rat plasma by using ultra-high performance liquid chromatography tandem mass spectrometry. Talanta. 2018;185:71-9.

29. Şenocak A, Köksoy B, Demirbaş E, Basova T, Durmuş M. 3D SWCNTs-coumarin hybrid material for ultra-sensitive determination of quercetin antioxidant capacity. Sensors and Actuators B: Chemical. 2018;267:165-73.

30. Hua Z, Deng Y, Li K, Yang S. Low-density nanoporous iron foams synthesized by sol-gel autocombustion. Nanoscale Research Letters. $2012 ; 7(1): 129$.

31. Tadic M, Panjan M, Damnjanovic V, Milosevic I. Magnetic properties of hematite (aFe203) nanoparticles prepared by hydrothermal synthesis method. Applied Surface Science. 2014;320:183-7.

32. Stöber W, Fink A, Bohn E. Controlled growth of monodisperse silica spheres in the micron size range. Journal of Colloid and Interface Science. $1968 ; 26(1): 62-9$.

33. Şenocak A, Khataee A, Demirbas E, Doustkhah $E$. Ultrasensitive detection of rutin antioxidant through a magnetic micro-mesoporous graphitized carbon wrapped Co nanoarchitecture. Sensors and Actuators B: Chemical. $2020 ; 312: 127939$.

34. Ersin D, Ahmet S, Mouhoum FT-K, Erhan D, Hassan YA-E. Electrochemical Evaluation of the Total Antioxidant Capacity of Yam Food Samples on a Polyglycine-Glassy Carbon Modified Electrode. Current Analytical Chemistry. 2020;16(2):176-83.

35. Şenocak A, Basova T, Demirbas E, Durmuş $M$. Direct and Fast Electrochemical Determination of Catechin in Tea Extracts using SWCNT-

Subphthalocyanine Hybrid Material. Electroanalysis. 2019.

36. Zhang $Z$, Gu S, Ding $Y$, Shen $M$, Jiang $L$. Mild and novel electrochemical preparation of $\beta$ cyclodextrin/graphene nanocomposite film for super-sensitive sensing of quercetin. Biosensors and Bioelectronics. 2014;57:239-44.

37. Wang $M$, Zhang $D$, Tong $Z$, Xu X, Yang X. Voltammetric behavior and the determination of quercetin at a flowerlike $\mathrm{Co} 3 \mathrm{O} 4$ nanoparticles 
modified glassy carbon electrode. Journal of Applied Electrochemistry. 2011;41(2):189-96.

38. Karimi-maleh H, Gupta V, Golestani F, Ahmadzadeh S, Fazli G, Khosravi S. NiO/CNTs Nanocomposite Modified Ionic Liquid Carbon Paste Electrode as a Voltammetric Sensor for Determination of Quercetin. International journal of electrochemical science. 2014;10:3657-67.

39. Sun S, Zhang M, Li Y, He X. A molecularly imprinted polymer with incorporated graphene oxide for electrochemical determination of quercetin. Sensors (Basel). 2013;13(5):5493-506.
40. Wang S, Xu Q, Liu G. Differential Pulse Voltammetric Determination of Uric Acid on CarbonCoated Iron Nanoparticle Modified Glassy Carbon Electrodes. Electroanalysis. 2008;20(10):1116-20.

41. Şenocak A, Köksoy B, Akyüz D, Koca A, Klyamer D, Basova $T$, et al. Highly selective and ultra-sensitive electrochemical sensor behavior of 3D SWCNT-BODIPY hybrid material for eserine detection. Biosensors and Bioelectronics. 2019;128:144-50. 